\title{
A Social Network Perspective of Building Information Modelling (BIM) in Greek Construction Projects
}

\section{Sulafa Badi and Dimitra Diamantidou}

The Bartlett, School of Construction and Project Management, University College London (UCL), 1-19 Torrington Place, London, WC1E 6BT, Sulafa Badi: s.badi@ucl.ac.uk,Dimitra Diamantidou: dimitra.diamantidou.13@alumni.ucl.ac.uk,

To cite: Badi, S. and Diamantidou, D. (2017), A Social Network Perspective of Building Information Modelling (BIM) in Greek Construction Projects, International Journal of Architectural Engineering and Design Management. 


\title{
A Social Network Perspective of Building Information Modelling (BIM) in Greek Construction Projects
}

\begin{abstract}
Building information modelling (BIM) is a technology promoted by governments as a solution to the problems of inefficient communication and limited collaboration in the construction industry. However, there remains a limited understanding of the changes that BIM introduces to the structure of inter-organizational communication and its impact on project participants' roles and relationships. In this study, these issues are addressed through a comparative study of two construction projects in Greece: one that utilized BIM, and one that did not. Social network analysis (SNA) was employed as an analytical method to examine the inter-organizational communication networks in relation to two types of information exchange- design development and cost management during the design stages of the two projects. Comparative SNA studies were conducted focusing on network density, tie strength, path length, and actor centrality. The research findings revealed the capacity for BIM to improve inter-organizational communication with the BIM-enabled project, exhibiting a higher density of communication, stronger ties, and shorter path lengths between project participants, indicating timely access to higher quality of information. The findings also identified the high centrality of the 'BIM manager' and 'BIM coordinator', demonstrating the effectiveness of these two new roles in managing the flow of communication in construction teams.
\end{abstract}

Keywords: building information modelling (BIM); social network analysis (SNA); communication networks; construction industry; Greece.

\section{INTRODUCTION}

Building Information Modelling (BIM) is a significant technological innovation in the Architecture, Engineering, and Construction (AEC) industry (Becerik-Gerber and Kensek, 2009). The increasing complexity of construction (Bryde et al., 2013) and the escalating demand for interoperability, multidisciplinary collaboration, and reciprocal exchange of vast amounts of 
information led towards the development and adoption of BIM (Singh et al., 2011). BIM comprises a core knowledge and communication resource for information about the facility, which is retained throughout the project's life cycle (NIBS, 2007). BIM has rapidly regenerated and re-established the way in which construction projects are conceptualized, designed, constructed, and managed (Hardin, 2009). It substitutes the traditional processes of the workflows in construction, establishing an "integrated and interoperable flow where tasks are collapsed into a coordinated and collaborative process” (Eastman et al., 2011, p. 17). BIM is seen to respond to a number of United Kingdom (UK) government reports' recommendations for the construction sector to employ and support collaborative functioning to drive successful project delivery (Latham, 1994; Egan, 1998).

Central to the entire discipline of BIM is the concept of collaboration (Barlish and Sullivan, 2012; Mondrup et al., 2012). A growing body of literature has investigated the collaborative benefits of BIM (Papadonikolaki, 2016; Cidik et al., 2014; Azhar, 2011). BIM is seen to support collaboration and provide the various stakeholders with a platform to share, interchange, and streamline data into a single model at different stages of the project life cycle (Eastman et al., 2011; NBIS, 2007; AECOM 2012; BIM Industry Working Group, 2011; RICS, 2012; Bryde et al., 2013). Much of the current literature on BIM pays particular attention to communication with BIM theorized to support the development of communication by introducing new roles and creating a portal towards facilitating effective communication among project actors (Papadonikolaki, 2016; Eastman and Nelly, 2011; National Institute of Building Sciences, 2007). Terms such as 'BIM manager' and 'BIM coordinator' are often used to describe new actor roles and disciplines which are responsible for project integration and coordination (Eastman et al., 2011).

The literature, then, has made a promising start in describing the collaborative benefits of BIM implementation. The extant literature, though, is silent regarding how BIM changes the structure of relationships among project actors. Indeed, there remains an ambiguous climate as regards BIM's core competencies, i.e. the collaboration, communication, and overall information-sharing and coordination in project delivery (Sebastian, 2011; Mignone et al., 2016). Major reports on the construction industry have underlined the need for further clarity in the roles of the project actors, and the relationships between them in BIM (BIM Industry 
Working Group; 2011; HM Government, 2012). Hence, having as a guideline the aforementioned literature and academic studies on BIM, the purpose of this paper is to attend to this gap in knowledge with the main objective of investigating the effect of BIM on changing the structure of relationships in construction projects and examining the significance of the new roles that BIM introduced.

The framework of this research is based on a relational perspective of construction projects which is directed towards a social network model of BIM. Described as a "temporary project coalition” (Winch, 1989, p. 336), a 'construction project' is defined as a network of organizations bounded by flows of information exchange and communicational networks of relationships (Pryke, 2012). We ask the following questions:

- What are the distinct relational and structural network characteristics created by BIM?

- What are the distinct network roles played by the newly introduced BIM roles?

We particularly focus on the social network concepts of cohesion (Reagans and McEvily, 2003) and actor prominence (Freeman, 1979). We propose that the introduction of BIM will increase the cohesion of the communication network among project actors in terms of increased density of the information-exchange network, reduced path length, and the increased strength of tie among project network actors. We also propose that BIM will introduce network structures in which prominent positions are occupied by those new disciplines introduced by BIM for the facilitation of information exchange, being the BIM manager and the BIM coordinator.

The opportunity to bring these theoretical issues to bear on the actual analysis of BIM in construction projects is provided by relational data that was collected from two projects in the Greek construction industry within BIM Level 2 at the design stage (RIBA work stages C-E (Royal Institute of British Architects, 2012). Social network analysis (SNA) was employed as a tool to analyze and visualize relationships between the different project actors (Pryke, 2012). The relationships among the project actors are investigated by means of the frequency and quality of their communication. The analysis and discussion of the findings will lead to conclusions regarding the overall effectiveness of BIM towards fostering increased cohesion among construction project stakeholders and the prominence of the new roles that BIM has 
introduced. The incentive towards developing a social network model of BIM has been to shift the focus from technical and legal issues of BIM towards a focus on the individuals and their relationships towards the delivery of successful projects (Pryke, 2012; Chinowsky et al., 2008).

\section{BUILDING INFORMATION MODELLING AND COMMUNICATION}

The excessive complexity of the construction projects requires multidisciplinary communication and collaboration that involve massive amounts of building data. Traditionally these critical issues had been resolved by means of the exchange of $2 \mathrm{D}$ designs and documentations (Singh et al., 2011). With the emergence of BIM, a model has been provided that incorporates all factors, disciplines, and systems of the facility within a single, virtual, and implicit model, authorizing all the project subscribers to collaborate and communicate more accurately, efficiently, and productively (Crotty, 2012). Driven by the escalating demand for higher integration of the construction domain, Grilo and Jardim-Goncalves (2010) suggested that the coordination of complex construction systems is facilitated by the implementation of BIM. A prerequisite, however, of an effective application of BIM is the early involvement and support of all project stakeholders to facilitate its use throughout the project life cycle (Azhar et al., 2012). BIM can be employed by the project owner to conceptualize project requirements, by the designers to analyze and develop the project, by the contractor to direct the construction, and by the facility administrator to manage the operation and decommissioning stages (Grilo and Jardim-Goncalves, 2010).

Indeed, the implementation of BIM could spread over the entire life cycle of a facility. Four distinct levels of maturity in the usage of BIM have been introduced (British Standards Institution, 2013). Specifically, BIM involves 4 maturity levels; Level 0, Level 1, Level 2 and Level 3. BIM Level 0, which is also known as the 'unmanaged CAD', constitutes the most basic level of BIM. No collaboration takes place between project actors with data comprising 2D CAD designs either in the form of paper or in an electronic format (e.g. Portable Document Formatpdf). BIM Level 1, on the other hand, is referred to as the 'managed CAD in 2 or 3D'. At this level, a 'common data environment' is implemented, allowing the project actors to share and 
exchange information. However, collaboration remains limited between the different disciplines as each actor publishes and maintains its own data (British Standards Institution, 2013). A higher maturity level is represented by BIM Level 2 which is characterized by collaborative working with design information being shared among project actors through a common file format. This allows any project actor to combine that data with their own in order to create a federated BIM model, and to check and interrogate it. This level not only involve 2D and 3D modelling but can also include dimensions such as 4D (construction scheduling) and 5D (cost) (Department of Business, Innovation and Skills, 2011). The highest level of maturity is BIM Level 3 which entails a fully integrated process in which all disciplines are coordinated, operating on a 'single' and 'open' BIM under a collaborative model server, incorporating not only 4D and 5D data, but also 6D (facilities management) (Royal Institute of British Architects, 2012).

This study is particularly focused on BIM Level 2 at the design stage (RIBA work stages C-E). BIM is seen to generate a platform that encourages the design team to communicate and participate at the early stages of the design-development process, enabling integration of multidisciplinary information (Reddy, 2012). Disputes rooted in the order change, specifications, and delayed issuance of construction designs could be largely eliminated, giving rise to higher levels of productivity. Internal contradictions related to documentations and drawings are disposed, whereas consistency is highly encouraged, leading to an efficient and effective design process, facilitating optimum communication within the project teams. The visualization of layout models can also bridge the gap between the design and site teams, reducing any buildability and fragmentation issues (Kaner et al., 2008; Eastman et al., 2008). Indeed, the most critical benefit of BIM proposed by Crotty (2012) is that all information related to the project's lifecycle is “generated and contained within the project's single BIM model or database” evolving according to the project's needs and aiming to optimize the project delivery and final outcome (Cotty, 92012 p. 46). The work of Papadonikolaki et al. (2016) also underlined the high interdependency between BIM and the collaborative concept of supply chain management (SCM). BIM can technically support SCM practices by regulating the information flow between the supply chain partners, while the long-term trusting relationships of SCM may create the collaborative environment necessary for BIM to be successfully implemented. However, while these benefits have been highly contended by BIM's proponents, there remain calls for further research to support these claims in practice (Sebastian, 2011; Migonone et al., 2016). Indeed, Mignone et 
al (2016) identified several barriers to successful collaboration in BIM-based construction networks including the differences in context among project actors and their dispersion both geographically and temporally as well as the imbalance in team configurations. Mignone et al (2016) emphasised the need for effective task-oriented leadership and sequential process management to support collaboration in BIM enabled networks.

In addition, the introduction of BIM has led to the emergence of new roles within the sector, with the terms 'BIM manager', and 'BIM coordinator' having been introduced and often used interchangeably (Eastman et al., 2011). The BIM manager is responsible for the guidance on the key liabilities and functions concerning the management of the information flow and data exchange, while retaining the 'model production and delivery table' up to date and according to the required levels of accuracy. On the other hand, the BIM coordinator has a distinct design role with responsibilities extending from coordinating the project model to undertaking clash detection. Among the duties are the generation of the BIM coordination plan, the management and implementation of quality-control inspections, and the application and installation of the software requirements and standards while retaining reports on the information exchange and communication patterns (BIM Industry Working Group, 2011). It must be highlighted, however, that the nature and importance of these new roles within the project delivery as well as the overall project life cycle are not clearly determined (BIM Industry Working Group, 2011; HM Government, 2012). Hence, this research aims to fill this gap by investigating the significance of these emerging roles that BIM introduced.

\section{TOWARDS A SOCIAL NETWORK MODEL OF BIM}

The second half of the 20th century has seen a critical surge of interest in research and the analysis of networks with the framework of organizational structure and management (Butts, 2009). Focusing on the communication patterns and information flow of social structures, management theories have shifted from individualistic, egocentric, and essentialist resolutions to a more relational, holistic, and contextual perception (Borgatti and Foster, 2003). Following the development of system and network ideas (Katz and Kahn, 1966), organizations have been conceptualized as social structures designed to operate by the collaboration and communication of individuals, linked by a variety of relationships (Kadushin, 2012; Pryke, 2012). Construction 
projects comprise temporary social systems involving a group of people who interact, creating communicational patterns and information networks (Winch, 2010).

Social network theory and the associated SNA was introduced as a conceptual lens and analytical tool for the study of the interactions among individuals engaged in construction projects. As defined by Wasserman and Faust (1994: 20) "A social network consists of a finite set or sets of actors and the relations defined on them." Hence, a construction project can be represented as a social structure involving a group of individuals interacting and communicating in continually evolving value-adding networks (Pryke, 2012). SNA offers a wide range of measures and analysis routines that can help in visualizing the changing roles and shifting relational patterns among project actors (Pryke, 2012; Pryke and Pearson, 2006). Table 1 provides definitions to the main concepts and terminology of SNA.

\section{*** INSERT TABLE 1 ABOUT HERE ***}

The main focus of this study is upon the concepts of cohesion and prominence, as will be described below.

\section{Network cohesion}

Network cohesion represents a family of concepts which describe the degree of connectivity of a network (Reagans and McEvily, 2003). Thus, at an aggregate level, cohesion creates micro-social norms, by which actors conceive themselves as a team, orienting their behaviour and attitude accordingly. Cohesive teams exhibit higher homogeneity, information-sharing, and superior performance (Lawler, 2001). Wasserman and Faust (1994) noted that there are three crucial elements affecting the network's cohesion: the number of ties an individual has, the strength of these ties, and how closely connected the group is. Hence the elements that directly influence cohesion are related to 'familiarity', 'reachability' and 'robustness' and they could be adequately described by network density, path length, and tie strength (Frank, 1995). Network density indicates the level of connectivity of a network and is defined as the ratio of the number of actual ties to the maximum possible ties. The values of density can vary from 0 to 1 , with the latter indicating that all actors are connected while the former suggests a group of isolates with no communication flowing among them (Wasserman and Faust, 1994; Scott, 
2000). Consequently density provides critical information not only about the cohesion among the actors but also about the speed at which knowledge, information, and resources are disseminated throughout the network (Hanneman and Riddle, 2005). Path length—also known as 'geodesic distance'-is another network measure which represents the distance between a pair of actors, indicating the speed of the information flow from the transmitter to the recipient. In this measurement, distance is determined based on the minimum number of links that must be crossed to get from one actor to another. The emphasis of this measurement is to identify the number of individuals who must act as intermediate steps in the transfer of information between the communication originator and the receiver. We propose that the introduction of BIM will increase the cohesion of the network in terms of the density of the information exchange network and it will reduce the path length among network actors. This is based on the premise that BIM presents project information in a single manageable resource; hence the actors involved are allowed to communicate and collaborate efficiently on a coordinated and common basis (Azhar, 2011). BIM develops and supports early collaboration and hence higher levels of information flow and interaction. This leads towards an integrated working environment promoting reciprocal communication while eliminating inherent uncertainties (Crotty, 2012).

Another important measure that represents the value of relationships among network actors is tie strength, which defines the nature of the interaction between actors highlighting the frequency and quality of their relationship (Pryke, 2012). Since relationships create value (Tsai and Ghoshal, 1998; Podolny and Baron, 1997) the ties between the actors can be experienced either as weak or as strong, depending on the levels of frequency and quality of communication. Strong ties are considered to be indispensable within a social structure since they foster social stability, trust, and reliable information flow (Coleman, 1988). On the other hand, the strength of weak ties stems from the research of Granovetter (1973), which found that weak ties constitute a vital source of novel information providing the potential for flexibility and adaptability to market changes. We propose that BIM will enable stronger ties between network actors, as they exchange more frequent and higher-quality information. The introduction of BIM provides a platform for continual up-to-date communication among the project actors. Higher quality is brought about by the automatic corrections made via BIM when changes take place, involving an advanced collaboration of multiple disciplines working at an increased accuracy and consistency throughout the whole design-production phase (Reddy, 2012). 


\section{Actor centrality}

Centrality is a group of measures that describe the 'prominence' and 'power' of a particular actor (Freeman, 1979). Indeed, social networks are inert and by themselves do not exert power; rather they provide the channels through which power can be exerted through positional advantages. An important social network concept that is employed to identify such positional advantages is centrality. Centrality involves an attempt to monitor and identify critical actors and their strategic locations in relation to the proportion and significance of their ties and their authority and power over the information exchange (Bonacich, 1987). Hence centrality measures an actor's relation and contribution to the cohesiveness of a network, revealing their prestige. One measure of centrality is particularly important for this study: 'betweenness'. Betweenness Centrality describes the number of times an actor falls in the shortest paths linking the other actors. It identifies brokerage or gatekeeping potential of information flow in the network by indicating "the actor in the middle", possessing a form of control and "interpersonal influence” over the communication paths (Wasserman and Faust, 1994). We propose that the introduction of BIM will produce a distinct network structure in which prominent brokerage positions will be occupied by those new disciplines introduced by BIM for the facilitation of information exchange, being the BIM manager and the BIM coordinator. Those actors' high betweenness will allow them the opportunity to manage information flowing to others in the network, thus acting as 'funnels' through which most communication travels across the network.

In conclusion, this research is set within the boundaries of BIM Level 2 at the design stage (RIBA work stages C-E) and building on the established theoretical framework of BIM and the literature on social networks. It will investigate the patterns of communication by the study of information exchange networks' cohesion (density, tie strength, and path length) and actor centrality. It was to investigate these issues that we undertook an in-depth study of two construction projects: one that utilized BIM, and one that did not. The comparison between BIMenabled and non-BIM-enabled projects will allow the assessment of the effectiveness of BIM in reorganizing actor roles and relations, which will be mapped and graphically represented using SNA (Pryke, 2012). The methods adopted will be explained in the next section. 


\section{RESEARCH METHOD}

\section{Context}

The present study was conducted in Greece. The construction industry is one of the most important sectors in the Greek economy (Karousos and Vlamis, 2008). The sector is largely fragmented with the majority of firms being family-owned Small and Medium-sized Enterprises (SMEs) and geographically dispersed as a result of the country's mountainous topography (Zantanidis and Tsiotras, 1998). The Greek construction industry has enjoyed a steady growth in the 1990s largely due to EU funding for new infrastructure projects such as roads and airports as well as the organisation of the Athens 2004 Olympics (Karousos and Vlamis, 2008). However, The Geek economic crisis post 2008 had a significant impact on the Greek construction industry with the industry experiencing a sharp decline in productivity. While construction activity was increasing steadily in 2006-2008 by an annual average of 8.6\%, it decreased significantly in the years 2009-2011 with an average decline of -10.4\% (Eriotis et al., 2013). The industry's contribution to GDP has also fallen from 11\% in 2006 to only $4 \%$ in 2013, and the construction workforce shrank from 589.000 people in 2008 to only 287.000 people in 2013 (Greek Institute for Economic and Industrial Research, 2015). However, even though the Greek economic and political uncertainties are ongoing, the Greek construction industry is expected to recover in 2016, growing by an annual 1.0\% and a real growth of 3.5\% year-on-year in 2017 (BMI, 2017). This is driven by the development of several non-residential projects and the construction of the Trans Adriatic Pipeline (TAP) (BMI, 2017).

BIM implementation remains in its infancy in Greece, with the BIM-enabled project studied in our research being the first of its kind in the country. However, there are calls for wider adoption of BIM in Greece, particularly among architects pursuing more collaborative approaches to design and to overcome the geographical dispersion of teams (Chatziandreou, and Kostopoulou, 2012). Indeed, as a consequence of the new challenging construction environment, BIM and its implementation is seen to be important to the success of the Greek construction industry particularly in terms of improved efficiency, productivity, collaboration, and meeting global trends in energy efficiency and sustainability (Chatziandreou, and Kostopoulou, 2012). 


\section{The Case-study Approach}

An exploratory case-study approach was considered to be best suited for this study as the researcher attempts to build rich, contemporary, and empirical descriptions of project team communication in an environment over which the researcher has no control (Yin, 2014). Adopting a comparative case approach, two construction projects were selected for investigation: one that utilized BIM, and one that did not (Eisenhardt and Graebner, 2007). The idea of case comparisons was based on replication logic, particularly theoretical replication (Yin, 2014) in that the two cases are expected to yield differing results for predictable reasons. Theoretical sampling means that cases are selected because they are particularly suitable for illuminating and extending relationships and logic among the concepts explored in the study. Table 2 provides a summary of the main characteristics of the projects.

\section{*** INSERT TABLE 2 ABOUT HERE ***}

The BIM project examined was the 'National Opera House' which, at the time the study was conducted, was the first and only project in Greece in which BIM was implemented; therefore the National Opera House formed a unique case (Yin, 2014) that was chosen for investigation. The selection of the non-BIM project was challenging due to the difficulty in identifying a project of exactly the same characteristics as the 'National Opera House' project for comparison. Indeed, 'no two projects, no two sites, and no two construction teams are ever exactly the same' (Macomber, 1989) and hence, to allow comparability, the non-BIM project- an 'Underground Station", was selected following a set of criteria as follows:

- Both projects are traditionally procured. The decision to select projects following a similar procurement route is based on the Sebastian (2011) which showed the effect of procurement on BIM.

- Both projects are of approximately similar cost.

- Both projects are entering the construction stage following the completion of the design-development stage. This was to ensure the recency of the 'window' by which participants were asked to recall their communication and hence increase the quality of the data collected. 


\section{Network Boundary and Data Collection}

An important decision that a network researcher needs to make is how to delimit the network under study, i.e. how to define the network boundary. The boundary of this study was set following a 'nominal' approach by the researcher as being the team working on the design development. This identified 28 actors for the non-BIM project and 30 actors in the BIM project. The data was collected following a quantitative SNA research approach using an online questionnaire (McQueen and Knussen, 2002). The statistical advantages of this quantitative research strategy are the ability to collect a large amounts of data and to analyze it in a logical and replicable manner (Fellows and Liu, 1997; Amaratunga and Baldry, 2001). Two initial meetings were held with the project managers associated with each project to introduce the aims and objectives of the research. Project participants were assured of their anonymity and that no identifying information would be used. The SNA questionnaire was designed to capture the communication patterns among the projects actors in terms of two types of information exchange:

- Design-development information (3D BIM- design and technical specifications)

- Cost-management information (5D BIM- contractors', subcontractors', and suppliers' costs and client's budget).

The SNA questionnaire was prefaced with space for primary information about each respondent, followed by definitions of each question. Detailed instructions were provided to support the internal validity and reliability of the data and to avoid the variability of the responses (Pryke, 2012). All actors were invited to choose from a pre-listed set of actors those individuals with whom they communicated in exchange of information during the design-development stage of the project. All types of communication were considered, including face-to-face talk, email, phone, and through the BIM-enabled platform. For each of the aforementioned communication patterns, the 'sent' and 'received' information exchanges were collected. Respondents were also asked to report, based on a Likert scale of the frequency of their communication (05), and the quality that was assessed (1-3). The scores for frequency and quality were multiplied and used as proxy for the evaluation of tie strength (Pryke, 2012).

\section{*** INSERT TABLE 3 ABOUT HERE ***}




\section{Data Analysis}

UCINET (Borgatti et al., 2002) was employed to analyze and evaluate the communication networks, whereas the graphic representation and interpretation of the networks was performed through the utilization of NetDraw and illustrated as sociograms (Pryke, 2012). The SNA concepts of network density, tie strength, path length, and actor centrality were employed to determine the communication patterns among network actors. A comparative analysis was conducted between the BIM-enabled and the non-BIM-enabled projects, as will be presented in the next section.

\section{RESULTS}

The following network diagrams in Figure 1 represent the communication and information flow among the project actors, displaying the pattern of relationship and the extent of interaction. The networks are socio-centric, or ' whole', in that they comprise of the relations between all actors within the teams under study. The ties are directed (i.e. originate from a source actor and reach a receiver actor), and valued (i.e. tie strength is measured on a scale according to the frequency and quality of the communication).

The design-development information networks (Figures 1a and 1b) are seen to be considerably denser and better connected than the cost information networks (Figures 1c and 1d). One isolate can be identified in the BIM design-development information network, the CEO. On the other hand, the network diagrams associated with cost management reveal a much larger number of isolates not engaged in the network. Compared to the BIM project, the non-BIM reveals a higher level of subgroupings connected by cut points, demanding critical actors to bridge the information and relationships. This may signal a need for a higher level of financial awareness.

\footnotetext{
*** INSERT FIGURE 1 ABOUT HERE ***
} 


\section{Network Cohesion}

\section{Density}

The measure of density shows the level of network connectivity, with values ranging from 0 to 1 (1: all actors are connected, 0 : none of the actors are connected). Table 4 presents the network density of the design-development and cost-management networks for the two projects respectively. It is shown that both projects display moderate levels of network density, with the exception of the cost-management network in the non-BIM project, in which connectivity was found to be weak. The information-sharing and communication among the project disciplines is slightly higher in the BIM project's design-development network. The higher level of connectivity between the design team, the technical department, and the suppliers will enable an early discovery of clashes, design errors, synchronization of design, construction, and programme-planning (Crotty, 2012; Hardin, 2009).

\section{*** INSERT TABLE 4 ABOUT HERE ***}

On the other hand, the cost-management networks reflect an observable difference between the two case studies, with the BIM project presenting a much higher density (0.105) compared to the project without BIM (0.065). The higher connectivity of the BIM-enabled project network may lead to more compliance with budget and project constraints. Following the statement of Eastman et al. (2011) and Bryde et al. (2013) BIM may support higher financial security, which is attributed to the early extraction of the cost estimates during the design stage and the explicit information flow among the project actors.

\section{Tie strength}

The strength of ties represents the frequency and quality of actors' relationships. In this study, when the value of a tie is 7-observed as a median value separating the higher half of the data sample-and above, it is classified as a strong tie. As Figure 2 illustrates, the BIM project displays a higher proportion of strong ties for both networks (design development $=74 \%$; cost management $=26 \%$ ) compared to the non-BIM project (design development $=69 \%$; cost management $=20 \%$ ). Actors involved in the BIM project hence exchanged more frequent and 
higher-quality information. It could also be noted that both projects display a low percentage of strong ties in their cost-management networks, perhaps an indication of the infrequent and standardized nature of cost information in projects.

\section{*** INSERT FIGURE 2 ABOUT HERE ***}

\section{Path length}

Path length, as a measure of network cohesion, represents the distance between a pair of actors, indicating the speed at which information flows from the transmitter to the recipient. As shown in Table 5 (see below), the BIM project displays marginally lower path lengths with the average path length on both projects, reaching approximately 2.25. This indicates that information from a transmitter will need about 2-3 steps to reach the recipient. Hence, these are considered efficient networks by which information travels fast (Pryke, 2012).

\section{*** INSERT TABLE 5 ABOUT HERE ***}

\section{Actor Centrality}

Betweenness is selected as a measure of an actor's prominence with actors enjoying high betweenness centrality, having the potential to act as information brokers. Table 6 lists the betweenness centrality scores for network actors while Figure 3 displays the network diagrams with the size of the node reflecting the betweenness of the actor; the larger the node, the higher the betweenness score.

\section{*** INSERT TABLE 6 ABOUT HERE ***}

The prominent actors in all four networks are the project managers, the site managers and the design managers scoring the highest rates of betweenness. They are the main information brokers and communication hubs in the networks, transferring information and enabling coordination between network actors. As regards the BIM project, the BIM manager does not seem to play a significant role within this network. The BIM coordinator, on the other hand, displays 
a moderate level of betweenness, effectively contributing to the information flow and overall coordination of the project delivery.

In relation to the design network of the non-BIM project, the project manager, the design manager, and the site manager are in control of the overall coordination circulating the information while exercising their power within the network. On the other hand, in the BIM-enabled project, while the project manager, the design manager, and the site manager assume high betweenness, the BIM coordinator occupies a strategic position acting as a broker, bridging the information, design, and technical specifications with the technical and design department.

\section{*** INSERT FIGURE 3 ABOUT HERE ***}

Regarding prominence in the cost-management network, as displayed in Figure 4, the high betweenness centrality of the project manager and the design manager in the non-BIM project illustrates a bridge between the design team and the managers' teams of the other divisions. Alongside the site manager, they are the most prominent actors of the network, implying their significant influence and control over the majority of the information. However, due to their strategic position as cut points in the structure of the network there is a danger that their removal will result in the network breaking into separate component that no longer communicate with one another. A similar issue is found with the project manager and the site manager who are seen to be in exclusive communication with the subcontractors. Finally, the client is shown to have a moderate role within the network as he communicates exclusively with the critical actors of the cost network: the project manager, the quantity surveyor, the Civil Engineer Technical Department and the site manager.

\section{*** INSERT FIGURE 4 ABOUT HERE ***}

On the other hand, the involvement of the emergent roles in the BIM project cost-management network is evident, see Figure 5. With the financial issues both the BIM manager and the BIM coordinator reflect a moderate level of betweenness centrality. Regarding the former, as a broker of budget details and information, reporting directly to the client, the quantity surveyor, and the project manager, they encourage and facilitate the financial coordination between the managing departments and the aforementioned disciplines. The BIM coordinator, who seems 
to have been benefiting from the well-connected relationship between the client, the quantity surveyor, the project manager, and the BIM manager, is in charge of coordinating the information flow between the designer, the technical departments, and the design manager. Overall, each actor proves to be competent in building direct relations with actors who are able to implement proposals and orchestrate the information exchange. Hence, it is clear that the contribution of the BIM manager and the BIM coordinator is important in the structure of the network, highlighting the significance of their emergence.

*** INSERT FIGURE 5 ABOUT HERE ***

\section{CONCLUSION}

Our study extends the work of Mignone et al (2016) and Papadonikolaki et al. (2016) on the role of BIM in improving collaborative inter-organisational relations by providing quantitative evidence of the changes introduced by BIM. From the analysis of the indices and network diagrams produced from UCINET and NetDraw respectively, distinct relational and structural network characteristics introduced by BIM have been observed. In terms of both networks, design development, and cost management, the BIM-enabled project has shown a denser more cohesive inter-organizational communication structure facilitating collaboration among network actors. The path length among the actors is shorter, whereas the links between them are for the most part directly eliminating the odds of network fragmentation. Since the project actors work collaboratively from the early stages of the project life cycle (NBIS, 2007; RICS, 2012; BSI, 2013), the network stands at a more efficient level in transaction-cost terms due to increased familiarity between the actors, reduction of disputes and opportunistic behaviour, and the potential for component standardisation (Williamson, 1985; Winch, 1989; Pryke, 2012). The overall higher quality of communication is evidenced through the higher tie strength between the network actors. This supports the claims of Eastman et al. (2011) and British Standards Institution (2013) in that BIM encourages multidisciplinary collaboration and reciprocal communication. Design ambiguities may also be eliminated, whereas consistency and clarity are encouraged leading to an efficient and effective design process (Eastman et al., 
2011). However, due to the high percentage of isolated actors in the cost-management network, a higher level of financial awareness and contribution would have been more desirable.

In addition, we emphasised that networks are inert and by themselves do not exert power; rather they provide the conduits through which power can be exerted through positional advantages. An important social network concept that was adopted in this study to identify 'prominence' and 'power' of particular actors is betweenness centrality. The study observed the distinct network roles played by the newly introduced BIM disciplines: the BIM coordinator and the BIM manager. Both actors displayed moderate levels of betweenness centrality, indicating that they are playing a recognizable brokerage role within the communication flow. In terms of the design-development network, with the federated information being coordinated and communicated by both the BIM coordinator and the BIM manager, design discrepancies are more likely to be directly identified and addressed (Eastman et al., 2011; Cotty, 2011). On the other hand, regarding the cost-management network, a higher customer service and production quality should be expected with cost- and schedule-compression leading to greater rates of profitability (Hardin, 2009; Eastman et al., 2011).

Despite its exploratory nature, this study extends our knowledge of BIM as a social network model, with the results supporting the premise that BIM with its newly introduced roles builds a more connected relational environment, eliminating the risks and ambiguities of any network fragmentation. BIM could thus work as an effective communication asset for the construction industry.

Finally, a number of important limitations need to be considered. First, generalizability of these results is limited by the small sample size (two case studies) and by the geographic location (Greece). More case studies are needed to enable the generalizability of the findings. This limitation means that study findings need to be interpreted cautiously. The current study has examined BIM Level 2 at only the design stage (RIBA work stages C-E) and hence may not be representative of the whole project life cycle. It also exclusively examined design development and cost management information and excluded other levels of BIM (e.g. 4D and 6D). In addition, each construction project is unique and each construction company operates within a different organizational structure and culture; hence this research is offered as an illustrative example and may not be representative of the wider construction industry. Indeed, the paper 
has stimulated a number of questions requiring further research: for instance, an investigation is needed on the effects of the implementing of BIM at Level 3 on the communication, coordination, and information flow. Further work also needs to be done to establish whether BIM is influenced by the procurement route adopted, which could be pursued by investigating the communication patterns and information flow in projects following different procurement routes. There is also a need for a dynamic-network approach tracing the evolution of these networks throughout the project life cycle.

In conclusion, the social network perspective adopted in this study contributes to the literature on the role of BIM in improving collaborative inter-organisational relations (e.g. Mignone et al., 2016; Papadonikolaki et al., 2016). The case studies presented here provide some key analytical concepts on which to build a research agenda for the more detailed social network model of BIM-enabled construction projects.

\section{REFERENCES}

Azhar, S., Khalfan, M. and Maqsood, T. (2012). Building Information Modelling (BIM): Now and Beyond. Australian Journal of Cosnstruction Economics and Building, 12 (4), pp. $15-28$.

Azhar, S. (2011). 'Building Information Modelling (BIM): Trends, benefits, risks, and challenges for the AEC Industry', Leadership and Management in Engineering, 11(3), 241-52.

Barlish, K. and Sullivan, K. (2012). 'How to measure the benefits of BIM - A case study approach', Automation in Construction, 24, 149-59.

Becerik-Gerber, B. and Kensek, K. (2009). 'Building information modeling in architecture, engineering, and construction: Emerging research directions and trends', Journal of Professional Issues in Engineering Education and Practice, 136(3), 139-47.

BIM Industry Working Group (2011) A report for the Government Construction Client Group: Building Information Modelling (BIM) Working Party Strategy Paper. Her majesty’s Government, London.

BMI (2017), Greece Infrastructure Report, BMI Research, London, UK. 
Bonacich, P. (1987). 'Power and Centrality: A Family of Measures’, American Journal of Sociology, 92 (5), pp. 1170-82.

Borgatti, S., Everett, M. and Freeman, L. (2002). 'UCINET for Windows: Software for Social Network Analysis', Harvard, MA: Analytic Technologies.

Borgatti, S. and Foster, P. (2003). 'The Network Paradigm in Organizational Research: A Review and Typology’, Journal of Management, 29 (6), pp. 991-1013.

British Standards Institution (BSI) (2013). Specification for information management for the capital/delivery phase of construction projects using building information modelling. London: BSI.

Bryde, D. Broquetas, M. and Volm, J. (2013). 'The project benefits of Building Information Modelling' (BIM), International Journal of Project Management, 31(7), pp. 971-80.

Butts, C. (2009). 'Revisiting the Foundations of Network Analysis', Science, 325, pp. 414-16.

Chatziandreou, D. and Kostopoulou, M. (2012), BIM and Greek Construction: Research and Detailed Analysis for Potential Implementation, BSc thesis, Department of Architecture of the University of Thessaly, Greece.

Chinowsky, P., Diekmann, J. and Galotti, V. (2008). 'Social Network Model of Costruction', Construction Engineering and Management, 134 (10), pp. 804-12.

Cidik, M., Boyd, D. and Thurairajah, N. (2014, September 1-3). Leveraging collaboration through the use of building information models, Paper presented at the proceedings 30th annual ARCOM conference, Portsmouth, UK.

Coleman, J. (1988). Structural Holes: The Social Structure of Competition, Cambridge MA: Harvard University Press.

Crotty, R., (2012). The Impact of Building Information Modelling: Transforming Construction, Abingdon, Oxon: SPON Press.

Department of Business, Innovation and Skills (BIS) (2011). A report for the Government Construction Client Group: Building Information Modelling (BIM) Working Party Strategy Paper. London: BIS.

Eastman, C., Teicholz, P., Sacks R. and Liston, K. (2011). BIM Handbook: A guide to Building Information Modelling for owners, managers, designers, engineers and contractors, 2nd edn., Jersey, NJ: Wiley and Sons. 
Egan, J. (1998). Rethinking Construction, The Report of the Construction Task Force to the Deputy Prime Minister, John Prescott, on the scope for improving the quality and efficiencies of UK construction, London: HMSO.

Eisenhardt, K. and Graebner, M. (2007). 'Theory building from cases: opportunities and challenges’, Academy of Management Journal, 50 (1), 25-32.

Eriotis, N., Poutos, E., Retsinis, E., and Vasiliou, D. (2013). The Impact of Greek Economic Crisis on Profit of the Greek Construction Industry. International Journal of Economy, Management and Social Sciences, 2(7), 507-512.

Frank, K. (1995). ‘Identifying cohesive subgroups’, Social Networks, 17 (1), pp. 27-56.

Freeman, L. (1979). 'Centrality in social concepts: conceptual clarification', Social Networks, 1 (3), pp. 215-39.

Granovetter, M. (1973). 'The Strength of Weak Ties', American Journal of Sociology, 78 (6), pp. 1360-80.

Greek Institute for Economic and Industrial Research (2015), The collapse of the Greek construction sector, Greek Institute for Economic and Industrial Research, Athens, Greece.

Grilo, A. and Jardim-Gonclaves, R. (2010). 'Value proposition on interoperability of BIM and collaborative working environments', Automation in Construction, 19 (5), $\quad$ pp. 522-30.

Hanneman, R. and Riddle, M. (2005). Introduction to Social Network Methods, Riverside, CA: University of California, Department of Sociology.

Hardin, B. (2009). BIM and Construction Management, Indianapolis, IN: Wiley Publishing.

HM Government (2012), Industrial strategy - government and industry in partnership BIM (Building Information Modelling), London: HM Government, Department of Business Innovation and Skills.

Kadushin, C. (2012). Understanding Social Networks: Theories, Concepts, and Findings, 1st edn., Oxford: Oxford University Press.

Kaner, I., Sacks, R., Kassian, W. and Quitt, T. (2008). 'Case studies of BIM adoption for precast concrete design by mid-sized structural engineering firms’, Journal of ITcon, 13, pp. 303-23. 
Karousos, E., and Vlamis, P. (2008). The Greek construction sector: an overview of recent developments. Journal of European Real Estate Research, 1(3), 254-266.

Katz, D. and Kahn, R. (1966). The Social Psychology of Organizations, New York NY: Wiley and Sons.

Latham, M., (1994). Constructing the Team, Final Report of the Government/Industry Review of Procurement and Contractual Arrangements in the UK Construction Industry, London: HMSO.

Lawler, E. (2001). 'An Affect Theory of Social Exchange’, American Journal of Sociology, 107 (2), pp. 321-52.

Macomber, J. D. (1988). You can manage construction risks. Harvard business review, 67(2), 155-61.

Mignone, G., Hosseini, M., Chileshe, N. and Arashpour, M. (2016). 'Enhancing collaboration in BIM-based construction networks through organisational discontinuity theory: A case study of the new Royal Adelaide Hospital', Architectural Engineering and Design Management, 1-20.

Mondrup, T., Karlshøj, J. and Vestergaard, F. (2012). Communicate and collaborate by using building information modeling, Paper presented at the International Council for Research and Innovation in Building and Construction (CIB) W078 Conference, Beirut, Lebanon.

National Institute of Building Sciences (2007). National Building Information Modeling Standards: Overview Principles and Methodologies, National Institute of Building Sciences, United States (version 1: Part 1).

Papadonikolaki, E., Vrijhoef, R. and Wamelink, H. (2016). 'The interdependences of BIM and supply chain partnering: empirical explorations’, Architectural Engineering and Design Management, 1-19.

Podolny, J. and Baron, J. (1997). 'Resources and relationships: Social networks and mobility in the workplace', American Sociological Review, 673-93.

Pryke, S. (2012). Social Network Analysis in Construction, 1st edn., Oxford: Wiley and Sons.

Pryke, S. and Pearson, S. (2006). 'Project governance: case studies on financial incentives', Building Research and Information, 34 (6), pp. 534-45. 
Reagans, R. and McEvily, B. (2003). 'Network structure and knowledge transfer: The effects of cohesion and range', Administrative Science Quarterly, 48 (2), 240-67.

Reddy, K. (2012). BIM for Building Owners and Developmers: Making a Business Case for Using BIM on Projects. New Jersey NJ: Wiley and Sons.

Royal Institute of British Architects (RIBA) (2012). BIM Overlay to the RIBA Outline Plan of Work. London: RIBA.

Scott, J. (2000). Social Network Analysis: A Handbook, London: Sage.

Sebastian, R. (2011). 'Changing roles of the clients, architects and contractors through BIM', Engineering, Construction, and Architectural Management, 18 (2), 176-87.

Singh, V., Gu, N. and Wang, X. (2011). 'A theoretical framework of a BIM-based multi-disciplinary collaboration platform', Automation in Construction, 20 (2), 134-44.

Tsai, W. and Ghoshal, S. (1998). 'Social capital and value creation: The role of intrafirm networks', Academy of Management Journal, 41 (4), 464-76.

Wasserman, S. and Faust, K. (1994). Social Network Analysis: Method and Application, 1st edn., Cambridge: Cambridge University Press.

Williamson, O.E. 1985. The Economic Institutions of Capitalism: Firms, Markets, Relational Contracting, London, UK: Free Press/Collier Macmillan.

Winch, G. (1989). 'The construction firm and the construction project: a transaction cost approach', Construction Management and Economics, 7, pp. 331-45.

Winch, G. (2010). Managing Construction Projects, 2nd edn, Oxford: Blackwell Publishing Ltd.

Yin, R. (2014), Case Study Research: Design and Methods (Applied Social Research Methods) 5th Edn, Thousand Oaks: Sage publications.

Zantanidis, S., and Tsiotras, G. (1998). Quality management: a new challenge for the Greek construction industry. Total Quality Management, 9(7), 619-632. 


\section{Tables}

\section{Table 1: SNA main concepts and terminology}

\begin{tabular}{|c|c|c|}
\hline & & Definitions \\
\hline \multirow[t]{4}{*}{ Key concepts } & Social networks & Actors and relations between these actors \\
\hline & Actors (also nodes) & $\begin{array}{l}\text { Separate and distinct social entities, be they individu- } \\
\text { als, firms, or communities }\end{array}$ \\
\hline & $\begin{array}{l}\text { Relations (also links, ties, or } \\
\text { edges) }\end{array}$ & Social ties between pairs of actors \\
\hline & Subgroups & $\begin{array}{l}\text { Any subset of actors and relations between these ac- } \\
\text { tors }\end{array}$ \\
\hline \multirow[t]{4}{*}{ Basic elements } & Components & $\begin{array}{l}\text { Parts of the network that are connected within but dis- } \\
\text { connected from other parts of the network }\end{array}$ \\
\hline & Isolates & $\begin{array}{l}\text { Actors that are not connected to the remainder of the } \\
\text { network }\end{array}$ \\
\hline & Cut points & $\begin{array}{l}\text { Actors, if deleted, would divide the network into com- } \\
\text { ponents }\end{array}$ \\
\hline & Bridges & $\begin{array}{l}\text { Relations, the removal of which would result in a dis- } \\
\text { connected network with components }\end{array}$ \\
\hline \multirow[t]{3}{*}{$\begin{array}{l}\text { Network cohe- } \\
\text { sion }\end{array}$} & Density & $\begin{array}{l}\text { The percentage of the maximum possible number of } \\
\text { ties that are actually present }\end{array}$ \\
\hline & Path length & $\begin{array}{l}\text { The minimum number of links that must be crossed to } \\
\text { get from the information sender to the receiver }\end{array}$ \\
\hline & Tie strength & $\begin{array}{l}\text { The value ascribed to a tie, in our case calculated as } \\
\text { the frequency of communication multiplied by the } \\
\text { quality of the communication }\end{array}$ \\
\hline Centrality & Betweenness & $\begin{array}{l}\text { How many times an actor falls in the shortest path } \\
\text { connecting other actors }\end{array}$ \\
\hline
\end{tabular}

Sources: Wasserman and Faust (1994); Hanneman and Riddle (2005) 
Table 2: Project characteristics

\begin{tabular}{|l|l|l|}
\hline & \multicolumn{1}{|c|}{ Non-BIM project } & \multicolumn{1}{c|}{ BIM project } \\
\hline Type of project & Underground station & National Opera House \\
\hline Procurement & Traditional & Traditional \\
\hline Budget (cost) & $19,000,000-19,200,000 €$ & $18,500,000-19,000,000 €$ \\
\hline Duration & $1.5-2$ years & $1.5-2$ years \\
\hline
\end{tabular}




\section{Table 3: SNA questionnaire}

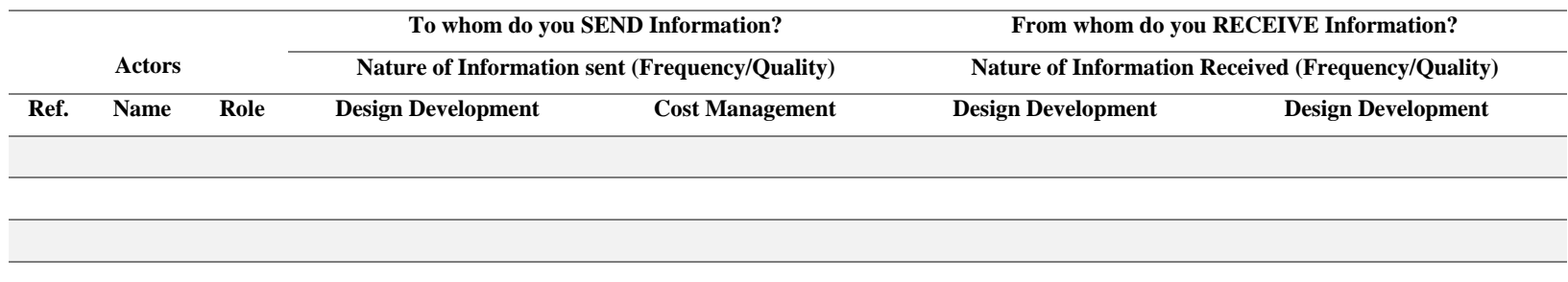

Note: frequency: $\mathbf{0}=$ never, 1=monthly, 2=fortnightly, 3=weekly, 4=several times week, 5=daily, 6=several times a day; Quality: 1=low, 2=medium, 3=high; Example: 5/3: daily information exchange of high quality. 
Table 4: Network density design-development and cost-management networks

\begin{tabular}{cccc}
\hline \multicolumn{2}{c}{ non-BIM Project } & \multicolumn{2}{c}{ BIM Project } \\
\hline Design development & Cost management & Design development & Cost management \\
\hline 0.226 & 0.065 & 0.230 & 0.105 \\
\hline
\end{tabular}


Table 5: Path length—Design-development and cost-management networks

\begin{tabular}{cccc}
\hline \multicolumn{2}{c}{ non-BIM Project } & \multicolumn{2}{c}{ BIM Project } \\
\hline Design development & Cost management & Design development & Cost management \\
\hline 2.099 & 2.465 & 2.027 & 2.444 \\
\hline
\end{tabular}


Table 6: Betweenness centrality

\begin{tabular}{|c|c|c|c|c|c|c|c|c|c|c|c|}
\hline \multicolumn{6}{|c|}{ non-BIM Project } & \multicolumn{6}{|c|}{ BIM Project } \\
\hline \multicolumn{3}{|c|}{ Design development } & \multicolumn{3}{|c|}{ Cost management } & \multicolumn{3}{|c|}{ Design development } & \multicolumn{3}{|c|}{ Cost management } \\
\hline 1 & CEO & 0.000 & 1 & CEO & 0.000 & 1 & CEO & 0.000 & 1 & CEO & 0.000 \\
\hline 2 & PM & 164.751 & 2 & PM & 70.333 & 2 & PM & 154.750 & 2 & PM & 54.938 \\
\hline 3 & DPM & 78.802 & 3 & DPM & 7.667 & 3 & DPM & 29.833 & 3 & DPM & 39.780 \\
\hline 4 & SM & 107.253 & 4 & SM & 50.167 & 4 & BM & 8.536 & 4 & BM & 7.510 \\
\hline 5 & ASM & 46.716 & 5 & ASM & 1.500 & 5 & $\mathrm{BC}$ & 87.583 & 5 & BC & 12.504 \\
\hline 6 & DM & 123.366 & 6 & DM & 42.000 & 6 & SM & 173.190 & 6 & SM & 51.280 \\
\hline 7 & ADM & 6.086 & 7 & ADM & 0.000 & 7 & ASM & 3.000 & 7 & ASM & 29.342 \\
\hline 8 & CWCM & 91.466 & 8 & CWCM & 0.000 & 8 & DM & 186.417 & 8 & DM & 72.358 \\
\hline 9 & M\&ECM & 22.196 & 9 & M\&ECM & 0.000 & 9 & ADM & 13.071 & 9 & ADM & 7.962 \\
\hline 10 & SCM & 0.000 & 10 & SCM & 0.000 & 10 & CWCM & 0.000 & 10 & CWCM & 43.743 \\
\hline 11 & PCM & 103.384 & 11 & PCM & 0.000 & 11 & M\&ECM & 0.000 & 11 & M\&ECM & 6.988 \\
\hline 12 & HSM & 0.000 & 12 & HSM & 0.000 & 12 & SCM & 0.000 & 12 & SCM & 0.000 \\
\hline 13 & QM & 0.000 & 13 & QM & 0.000 & 13 & PCM & 0.000 & 13 & PCM & 43.968 \\
\hline 14 & $\mathrm{SpM}$ & 0.000 & 14 & $\mathrm{SpM}$ & 0.000 & 14 & HSM & 0.000 & 14 & HSM & 1.952 \\
\hline 15 & QS & 0.000 & 15 & QS & 1.667 & 15 & QM & 0.000 & 15 & QM & 0.000 \\
\hline 16 & CETD & 26.071 & 16 & CETD & 0.000 & 16 & SpM & 0.000 & 16 & SpM & 0.000 \\
\hline 17 & ATD & 5.157 & 17 & ATD & 0.000 & 17 & QS & 23.310 & 17 & QS & 0.250 \\
\hline 18 & M\&ETD & 5.157 & 18 & M\&ETD & 0.000 & 18 & CETD & 41.881 & 18 & CETD & 11.311 \\
\hline 19 & SD & 22.643 & 19 & SD & 0.000 & 19 & ATD & 7.381 & 19 & ATD & 2.106 \\
\hline 20 & $A D$ & 4.355 & 20 & $A D$ & 0.000 & 20 & M\&ETD & 7.381 & 20 & M\&ETD & 2.106 \\
\hline 21 & M\&ED & 4.355 & 21 & M\&ED & 0.000 & 21 & SD & 0.000 & 21 & SD & 12.968 \\
\hline 27 & MCF & 0.090 & 22 & MCE & 0.090 & 22 & AD & 0.000 & 22 & $A D$ & 2.698 \\
\hline 23 & $\mathrm{~F}$ & 0.222 & 23 & F & 0.00 & 23 & M\&ED & 0.000 & 23 & M\&ED & 2.698 \\
\hline 20 & $r$ & 0.222 & 24 & CF & 0.000 & 24 & MCE & 0.000 & 24 & MCE & 0.000 \\
\hline 24 & CF & 0.722 & 24 & ${ }_{C F}^{C F}$ & 0.000 & 25 & $\mathrm{~F}$ & 0.000 & 25 & $\mathrm{~F}$ & 0.100 \\
\hline 25 & Sct-E & 0.000 & 25 & Sct-E & 4.333 & 26 & $\mathrm{CF}$ & 0.000 & 26 & $\mathrm{CF}$ & 0.433 \\
\hline 26 & Sct $-\bar{C}$ & 0.222 & 26 & Sct-C & 4.333 & 27 & Sct-E & 13.333 & 27 & Sct-E & 0.100 \\
\hline 27 & Sct-RS & 0.222 & 27 & Sct-RS & 4.333 & 28 & Sct-C & 13.333 & 28 & Sct-C & 0.100 \\
\hline \multirow[t]{2}{*}{28} & $\mathrm{Cl}$ & 17.853 & 28 & $\mathrm{Cl}$ & 16.667 & 29 & Sct-RS & 13.333 & 29 & Sct-RS & 0.100 \\
\hline & & & & & & 30 & $\mathrm{Cl}$ & 17.667 & 30 & $\mathrm{Cl}$ & 9.704 \\
\hline
\end{tabular}

Key

Non-BIM project: CEO: Chief Executive Officer, PM: Project Manager, DPM: Deputy Project Manager, SM: Site Manager, ASM: Assistant Design Manager, DM: Design Manager, ADM: Assistant Design Manager, CWCM: Civil Works Chief Manager, M\&ECM: M\&E Chief Manager, SCM: Surveying Chief Manager, PCM: Planning Control Manager; HSM: Health\& Safety Manager, QM: Quality Manager, SpM: Supplies Manager, QS: Quantity Surveyor, CETD: Civil Engineer Technical Department, ATD: Architect Technical Department, M\&ETD: M\&E Technical Department, SD: Structural Designer, AD: Architect Designer, M\&ED: M\&E Designer, MCE: Monitor Chief Engineer, F: Forman, CF: Chief Forman, Sct-E: Subcontractor Excavations, Sct-C: Subcontractor Concreting, Sct-RS: Subcontractor Retaining Structures, CI: Client.

BIM project: CEO: Chief Executive Officer, PM: Project Manager, DPM: Deputy Project Manager, BM: BIM Manger, BC: BIM Coordinator, SM: Site Manager, ASM: Assistant Design Manager, CWCM: Civil Works Chief Manager, M\&ECM: M\&E Chief Manager, SCM: Surveying Chief Manager, PCM: Planning Control Manager; HSM: Health\& Safety Manager, QM: Quality Manager, SpM: Supplies Manager, QS: Quantity Surveyor, CETD: Civil Engineer Technical Department, ATD: Architect Technical Department, M\&ETD: M\&E Technical Department, SD: Structural Designer, AD: Architect Designer, M\&ED: M\&E Designer, MCE: Monitor Chief Engineer, F: Forman, CF: Chief Forman, Sct-E: Subcontractor Excavations, Sct-C: Subcontractor Concreting, Sct-RS: Subcontractor Retaining Structures, CI: Client. 


\section{Figures}

\section{Figure 1: The networks}
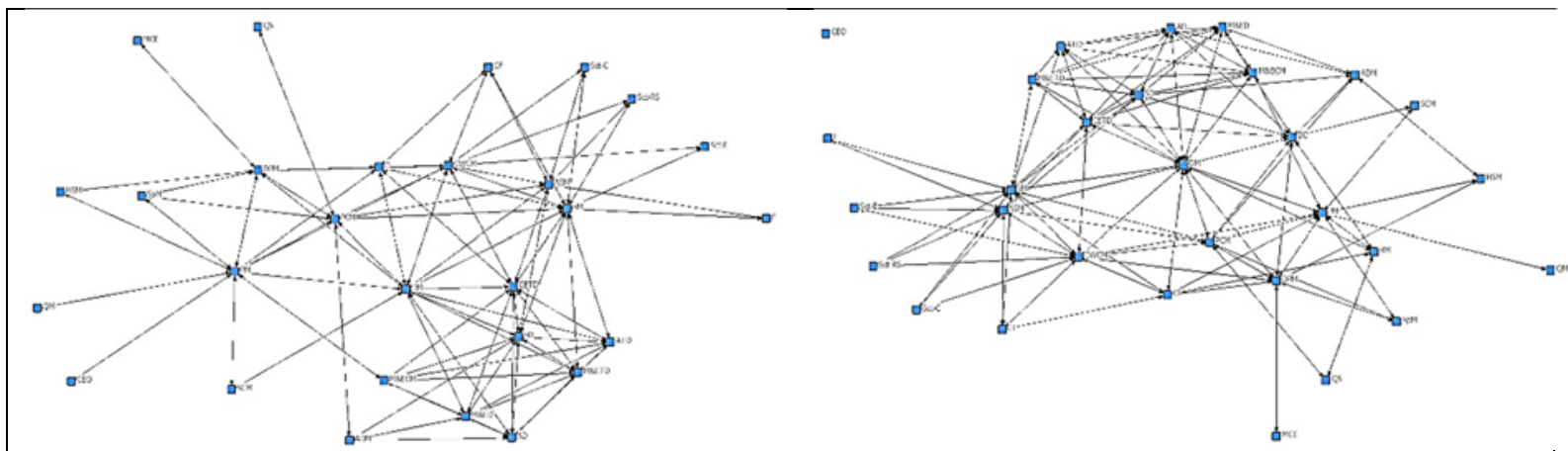

Figure 1a: Design-development network-Information flow in the non-BIM project

Figure 1b: Design-development network-Information flow in the BIM project
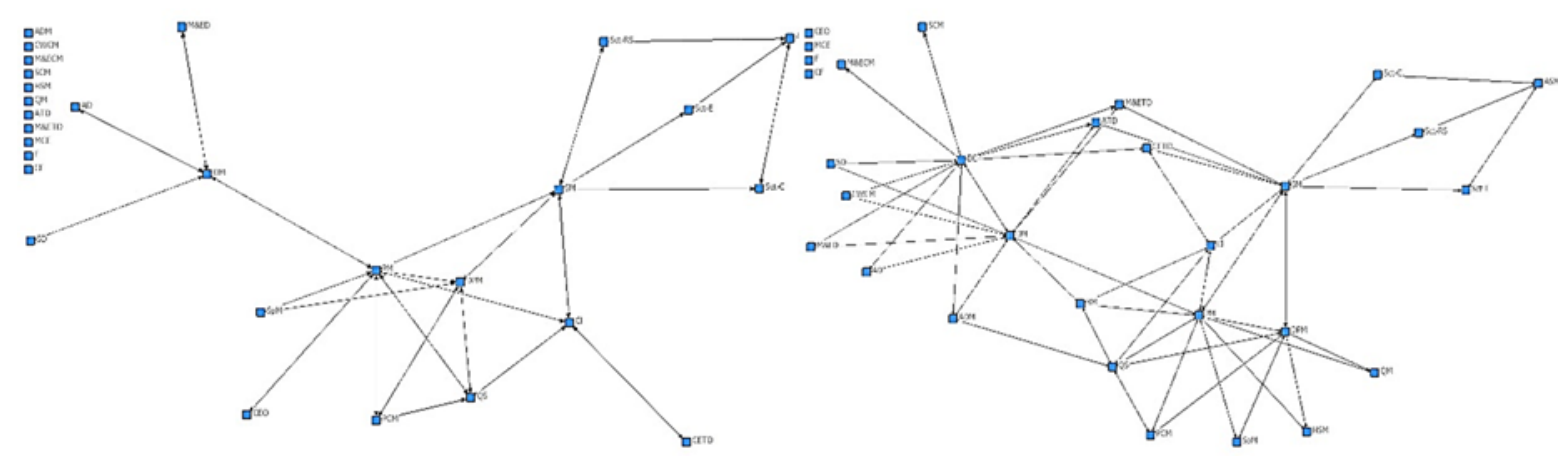

Figure1c: Cost-management network-Information flow in the

Figure 1d: Cost-management network-Information flow in non-BIM project the BIM project 
Figure 2: Tie strength

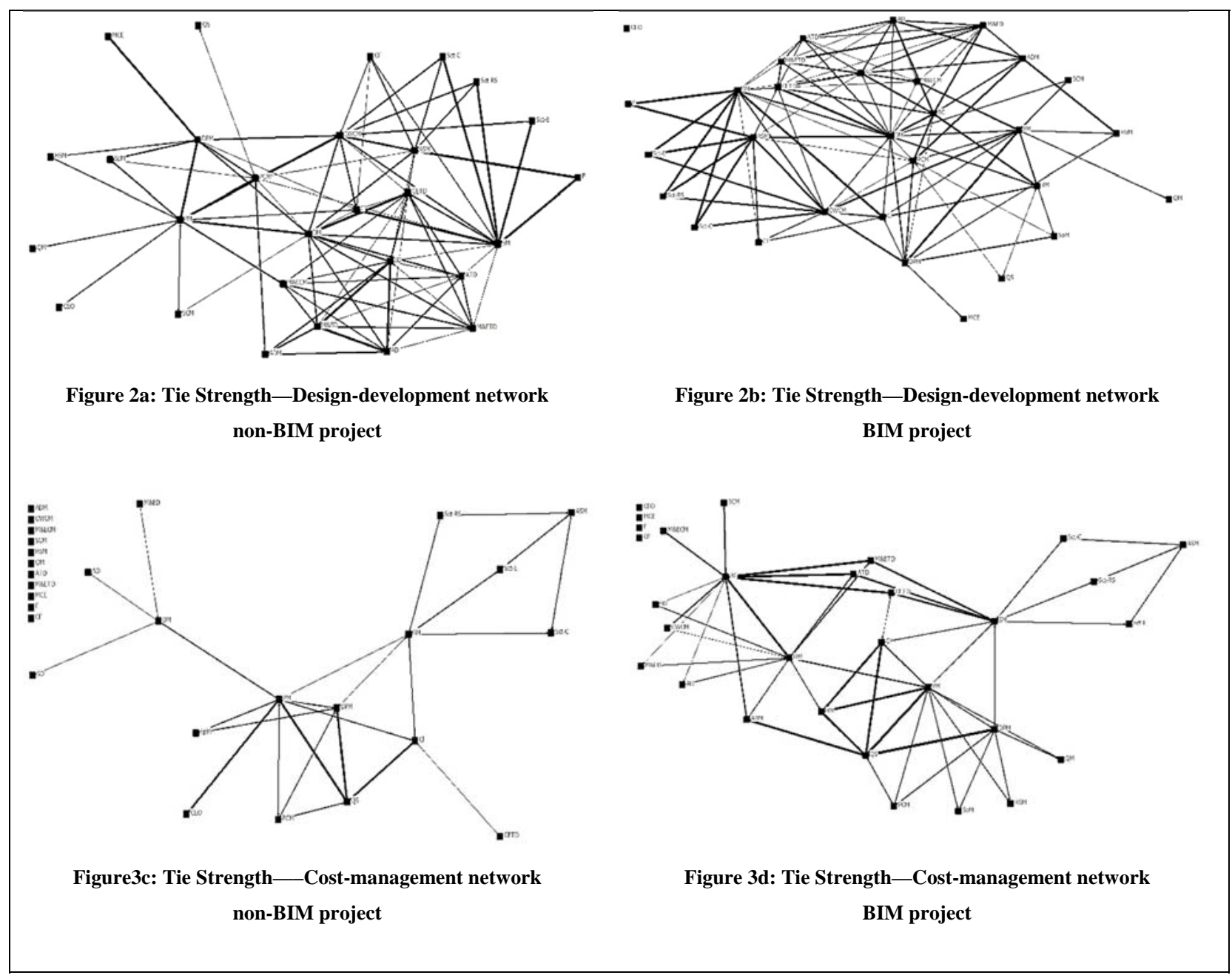




\section{Figure 3: Betweenness centrality}

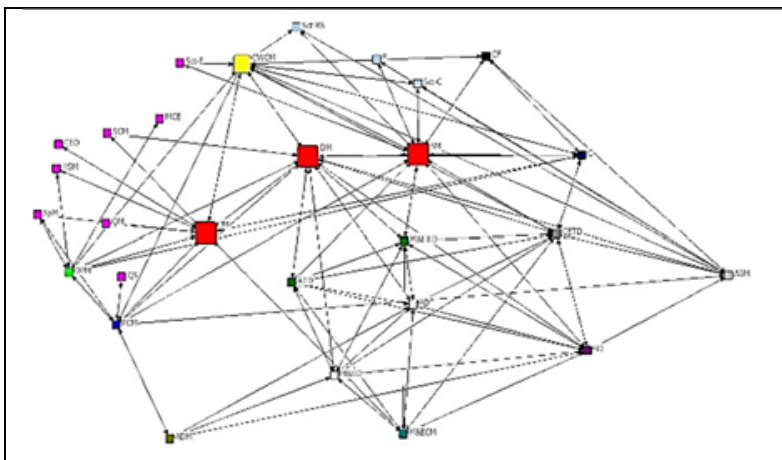

Figure 3a: Betweenness centrality-Design-development network-non-BIM project

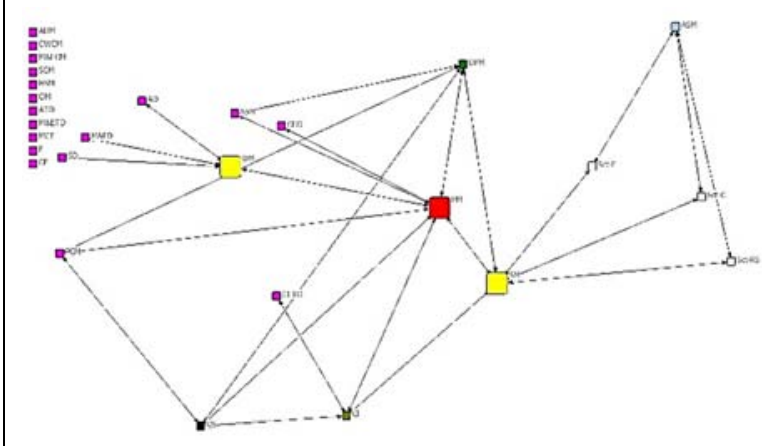

Figure 3c: Betweenness centrality-Cost-management network non-BIM project

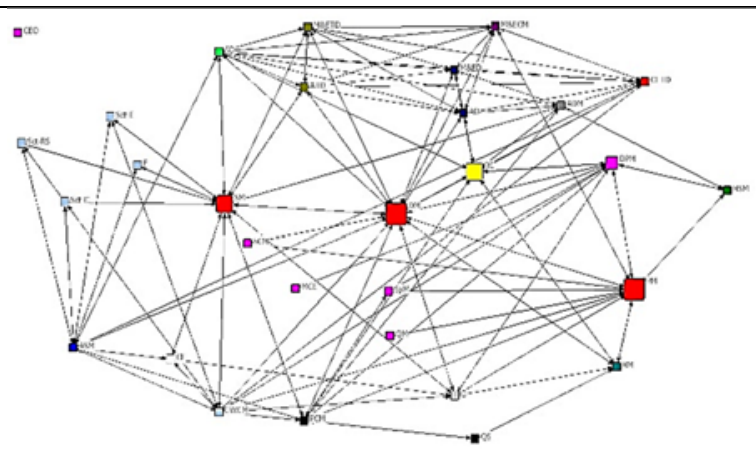

Figure 3b: Betweenness centrality-Design-development network BIM project

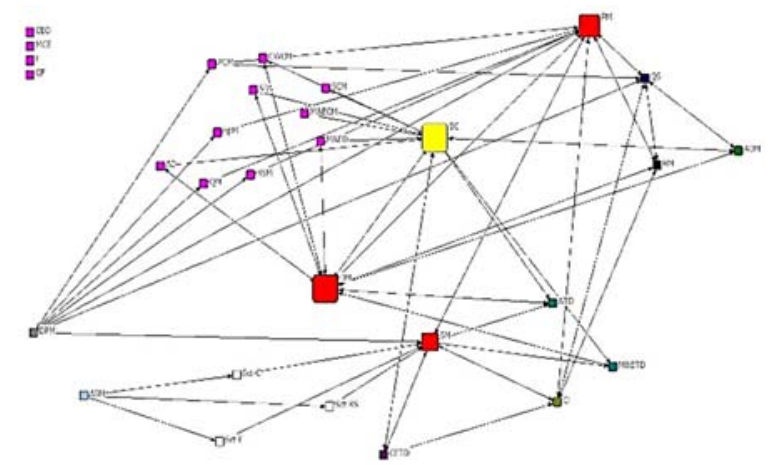

Figure 3d: Betweenness centrality-Cost-management network BIM project 
Figure 4: Prominence in the cost management network- non-BIM project

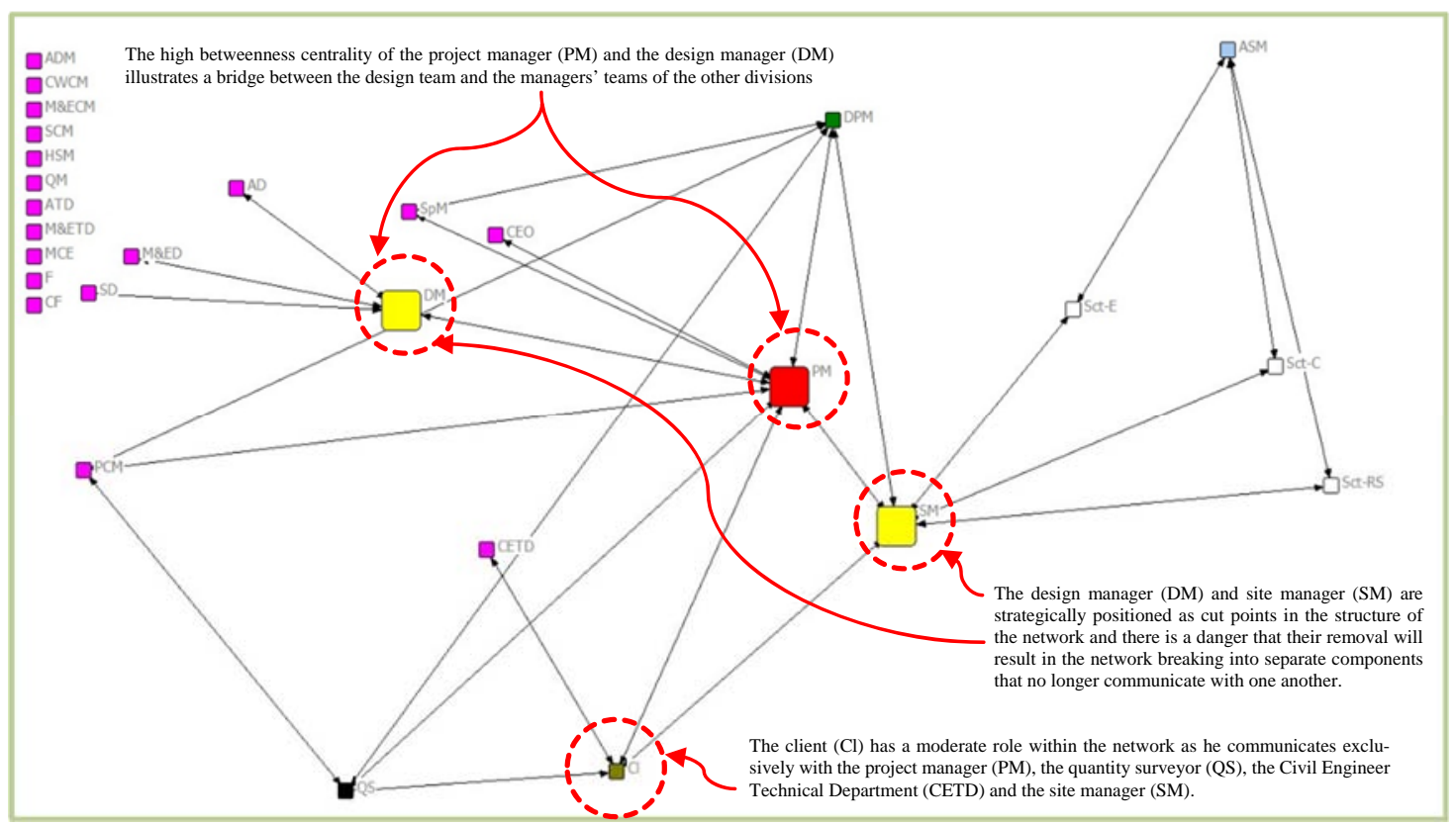


Figure 5: Prominence in the cost management network-BIM project

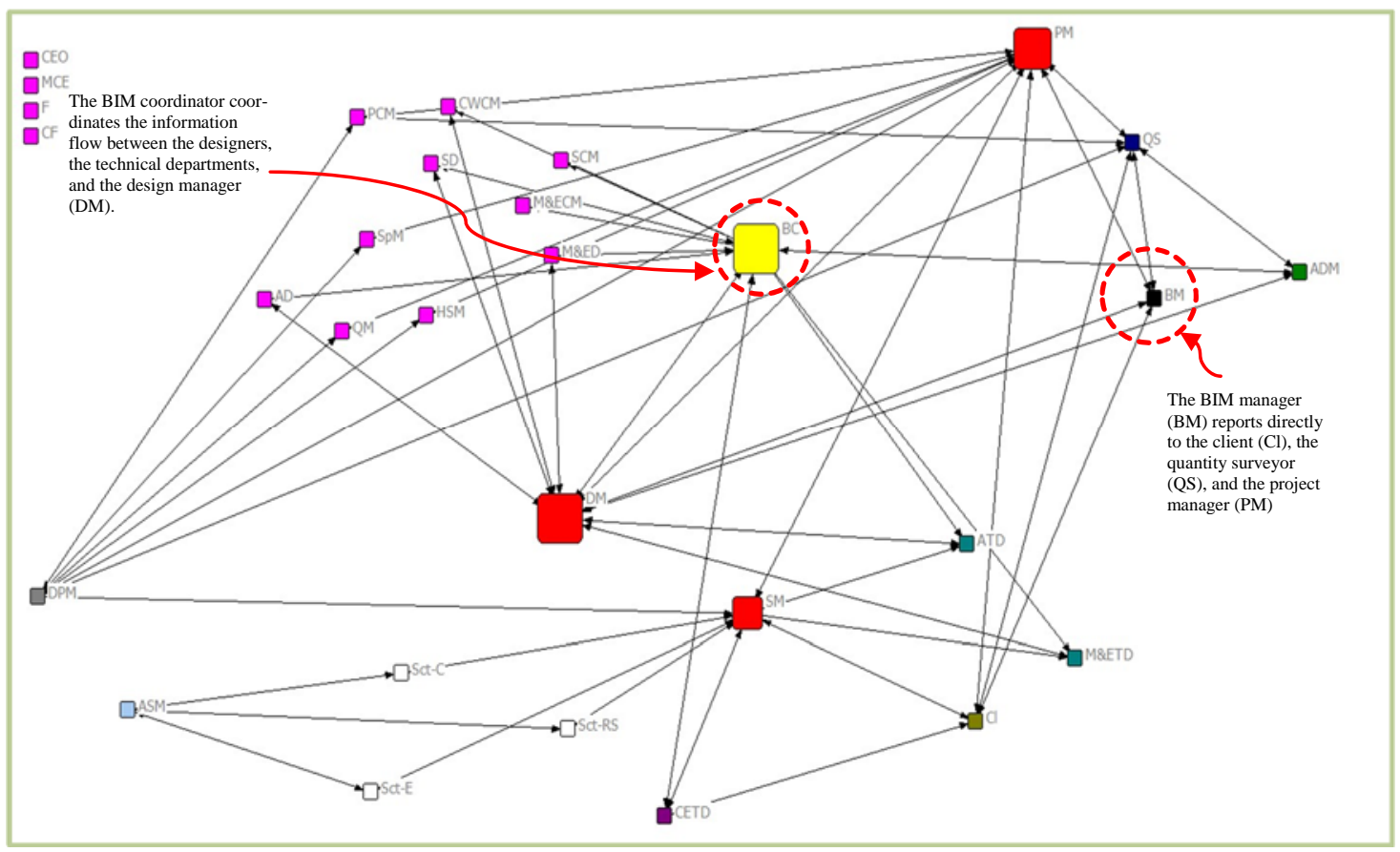

